\title{
la documentación al servicio de la industria de la construcción
}

ANTONIO COMYN

Jefe de la División de Información del I. E.T.

\begin{abstract}
Una de las notas más sobresalientes de la época en que vivimos es el marcado desvelo mundial por las técnicas de la Gerencia de Empresas y de la Organización Científica del Trabajo. En todas las naciones y ramas de la Industria los temas de Estudio de mercados, Productividad, Información Técnica y Documentación, Mecanización Administrativa, Control de la Calidad, Relaciones humanas, etc., son motivo continuo para la formación de Empresas Consultoras y para la impresión de millares de libros, artículos de revistas y folletos.
\end{abstract}

No es ya la empresa media, sino también las de tipo más reducido y capital más limitado las que han demostrado conceder a estas materias una singular atención y marcada importancia. Como consecuencia de ello, incluso en la Industria de la Construcción, rara es la empresa española que en los últimos diez años no se haya ocupado de considerar alguna o varias de las numerosas conquistas logradas en el campo de la Ciencia de la Gerencia.

No es menos cierto que, en nuestra coyuntura, se ha producido, de forma rápida, el decisivo paso de la organización dirigida y ejecutada por una sola persona, a la dirigida por un equipo o estructura orgánica, a cuya cabeza figura una persona cuya actuación se caracteriza por intervenir sólo en las decisiones. Fruto indudable del moderno concepto de empresa.

Pero en España, mientras que en este campo de la Ciencia de la Gerencia la Industria de la Construcción también atiende y aplica, con creciente interés, prósperos resultados y ritmo acelerado a gran parte de las técnicas y principios de esta Ciencia, estimamos se concede atención secundaria y escasa importancia a los servicios de Documentación. Es decir, a seguir al día los progresos de la Construcción en todos los órdenes, siendo así que estos servicios, incluso para la empresa mejor organizada, la que aplique con más perfección los principios y la técnica de la Gerencia, del «Management», pueden evitar que le llegue el fracaso y la ruina.

A los avances de la Ciencia y de la Técnica corresponde hoy el primer puesto entre las preocupaciones de las naciones. Los países que ocupan o aspiran a ocupar un lugar destacado en la vida internacional, se apoyan mucho más en la marcha y en el estado de sus descubrimientos científicos y técnicos, que en la capacidad ofensiva de sus efectivos militares y de sus unidades de combate.

A este estado de cosas responden las fabulosas cifras que las naciones destinan a la Documentación y a la Investigación. Los Estados Unidos invierten el 1,4 por 100 de la renta nacional; Alemania, el 1; Gran Bretaña, el 0,9; Francia, el 0,5, etc. En todos los países se tiene fe en la Información Científica como una de las fuentes más sólidas y fecundas de la riqueza nacional.

Por su parte, las empresas constructoras necesitan documentarse si aspiran a sobrevivir y a vencer la prueba, cada día más dura, de la competencia. La Documentación permite a la empresa su renovación evolutiva cotidiana, el conocimiento al día de los adelantos que se producen en su técnica y las noticias y novedades que más puedan afectarla; la pone al abrigo de hallarse un día con la dolorosa sorpresa de comprobar que su producción no tiene colocación posible en el mercado, por el alto nivel de sus precios, o por la inferior calidad de sus 
productos, o por la excesiva elevación de sus costes, etc. La empresa sin un servicio de Documentación se detiene en un determinado nivel, que desemboca, más tarde o más temprano, en el anquilosamiento y en la quiebra. El antiguo dicho «el que se para, retrocede», se formula hoy: «el que no corre a compás de los tiempos, se arruina».

La Documentación y sus admirables progresos técnicos son iniciativa y creación de arquitectos e ingenieros en su mayor medida. Han sido ellos los que, al querer mejorar las realizaciones de la Industria de la Construcción, han comprobado la necesidad ineludible de disponer de una fuente flúida de información, para acompañar y utilizar cotidianamente en su campo los avances de la Ciencia y de la Técnica. Han sido ellos los que, por un lado, frente a los millares de artículos de revistas y libros que ven anualmente la luz pública sobre toda clase de materiales, y de otro, ante la imposibilidad de adquirir y leer todo lo publicado de su interés, han contribuido decisivamente a la creación del Documentalista, cuya principal misión estriba en recoger, ordenar, seleccionar, clasificar, extractar y comunicar, circulándolos en el más breve espacio de tiempo, aquellos escritos y noticias que puedan contribuir eficazmente a mejorar la producción, la administración, etc., y lograr toda suerte de beneficios para la Empresa. A ellos se deben también, en función de los mismos propósitos, los numerosos mecanismos que a millares se han puesto al servicio de la reproducción, clasificación, selección y transmisión de documentos. A esta atención verdaderamente ejemplar, que los técnicos han dedicado al servicio de la Documentación, se debe la electrónica rapidez con que se desarrollan y suceden los descubrimientos diarios que se dan en las más variadas especialidades.

La Gerencia de la empresa se ha de apoyar-cada día con mayor auge-sobre el empleo, cada vez más productivo, de una Información obtenida después de una cuidadosa selección, hija de numerosos análisis y de la ponderación y combinación de las distintas variantes que, en torno a los supuestos lógicos, se presenten. El papel de la Gerencia es, más bien de coordinación que de omnímoda autoridad. La velocidad con que se transforman las industrias y la repercusión que sobre ellas tienen los avances, aun los surgidos en los campos más alejados de ellas, obligan a los empresarios a realizar planificaciones a largo plazo, que no consisten, en modo alguno, en predicciones aventuradas del futuro, sino en tomar decisiones con método, en presencia de unos datos y riesgos bien calculados. En todo ello es vital la intervención de una Documentación, bien seleccionada y circulada.

Las empresas constructoras no pueden cerrar los ojos a la marcha veloz que imprimen los arquitectos e ingenieros y los investigadores a los nuevos materiales, ingenios y creaciones. El empresario no puede vivir de cara a su industria exclusivamente, viendo año tras año salir de ella la misma producción, y mucho menos en los casos en que se enfrenten con perder una decidida protección aduanera. Tiene que volverle la espalda diariamente, durante cierto lapso de tiempo, para otear el horizonte, mirar al porvenir, y rectificar acomodando paulatinamente su industria a la lucha de los cinco, o todavía con preferencia de los diez años venideros. No se puede ignorar que en la actualidad se calcula que existen más de 15.000 investigadores de alto nivel y extraordinaria capacitación, con materiales, laboratorios y medios eficacísimos para la realización de prácticas y ensayos encaminados al perfeccionamiento de la Industria de la Construcción, y que este número alcanzará los 30.000 dentro de los próximos cuarenta años. Que los Estados Unidos, la Gran Bretaña y otros países han duplicado, en breve espacio de tiempo, el número de sus graduados, y que España está preparada para lograr un incremento sustancial. Que la competencia que se avecina ha de ser cada vez mayor.

Hemos considerado obligatorio dar cuenta de esta situación actual a nuestros lectores, con el convencimiento de que, de una forma u otra, se creará un auténtico sentido de responsabilidad con respecto a la Documentación. Un servicio productivo como el que más, y que requiere solamente la puesta en marcha para que sus dividendos sean contables a todos los efectos. 